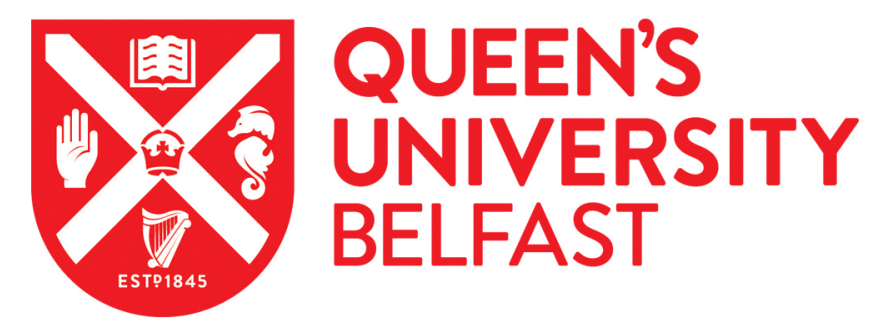

\title{
Broadband Dual-Polarized Antenna with High Port Isolation and Polarization Purity
}

Wolosinski, G., Fusco, V., \& Rulikowski, P. (2016). Broadband Dual-Polarized Antenna with High Port Isolation and Polarization Purity. In Conference Proceedings of 2016 IEEE International Symposium on Antennas and Propagation Institute of Electrical and Electronics Engineers Inc..

\section{Published in:}

Conference Proceedings of 2016 IEEE International Symposium on Antennas and Propagation

\section{Document Version:}

Peer reviewed version

\section{Queen's University Belfast - Research Portal:}

Link to publication record in Queen's University Belfast Research Portal

\section{Publisher rights}

(c) 2016 IEEE. Personal use of this material is permitted. Permission from IEEE must be obtained for all other uses, in any current or future media, including reprinting/republishing this material for advertising or promotional purposes, creating new collective works, for resale or redistribution to servers or lists, or reuse of any copyrighted component of this work in other works.

\section{General rights}

Copyright for the publications made accessible via the Queen's University Belfast Research Portal is retained by the author(s) and / or other copyright owners and it is a condition of accessing these publications that users recognise and abide by the legal requirements associated with these rights.

Take down policy

The Research Portal is Queen's institutional repository that provides access to Queen's research output. Every effort has been made to ensure that content in the Research Portal does not infringe any person's rights, or applicable UK laws. If you discover content in the Research Portal that you believe breaches copyright or violates any law, please contact openaccess@qub.ac.uk. 


\section{Broadband Dual-Polarized Antenna with High Port Isolation and Polarization Purity}

\author{
G. Wolosinski, V. Fusco \\ ECIT \\ Queen's University Belfast \\ Belfast, UK \\ g.wolosinski@qub.ac.uk,v.fusco@ecit.qub.ac.uk
}

\author{
P. Rulikowski \\ Wireless Access Dept. \\ Alcatel-Lucent Bell Labs \\ Dublin, Ireland \\ pawel.rulikowski@alcatel-lucent.com
}

\begin{abstract}
This paper presents a novel high symmetry balun which significantly improves the performance of dipole-based dual-polarized antennas. The new balun structure provides enhanced differential capability leading to high performance in terms of port-to-port isolation and far-field cross polarization. An example antenna using this balun is proposed. The simulated results show $53.5 \%$ of fractional bandwidth within the band 1.71-2.96 GHz $($ VSWR $<1.5)$ and port-to-port isolation $>59 \mathrm{~dB}$. The radiation characteristic shows around $9 \mathrm{dBi}$ of gain and farfield cross polarization $<-48 \mathrm{dBi}$ over the entire bandwidth. The detailed balun functioning and full antenna measurements will be presented during the conference. Performance comparison with similar structures will be also provided.
\end{abstract}

Keywords-Dual-polarized antenna; Port isolation; Cross polarization.

\section{INTRODUCTION}

In the last few years wireless communication systems require more spectrum resources to satisfy the coexistence of multiple standards within the same base station. For this reason, base station antennas are required to exhibit wide impedance bandwidth and dual polarization feature as well as high port-to-port isolation. Several antenna embodiments have been proposed to address these requirements [1]-[2]. However, albeit with the support of balun structures [3] these antennas find difficulties in achieving very high performance. In this paper a broadband dual-polarized antenna based on a novel balun is presented. The resulting antenna shows extremely high port-to-port isolation and low far-field cross polarization. The antenna operates within the band $1.71-2.96 \mathrm{GHz}$ and it is therefore suitable for base station applications.

\section{ANTENNA DESIGN}

The proposed antenna is depicted in Fig. 1 and consists of two cross dipoles, a dielectric support, a balun structure, and a metallic reflector. The dipoles are supported by the dielectric support $\left(\varepsilon_{r}=2.1\right)$ and fed through the balun which consists of two coaxial feeding cables and two metallic dummy cables with equal cross section. All the cables are connected to the dipoles in the same plane as the dipoles and bent toward the reflector according to four symmetric guides located around the dielectric support (see Fig. 1). In the central feeding section the external part of each cable is connected to the corresponding radiating element while the inner conductor of each feeding cable is attached to the opposite situated dummy cable. The two dipoles are identical to each other apart from their feeding structures which are symmetrically shifted to avoid physical overlap (see Fig. 1c). The feeding cables as well as the dummy ones pass through the reflector by means of four corresponding holes and are shorted to the latter resulting in a quarter-wave balun functioning for each dipole. Such a configuration minimizes the transition effect from a coaxial cable (unbalanced structure) to a dipole antenna (balanced structure) providing a highly balanced feed and therefore highly symmetrical current distribution onto the antenna.

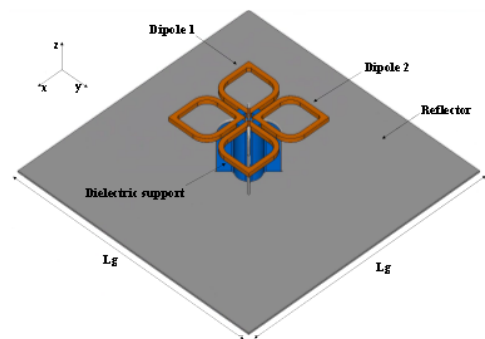

(a)

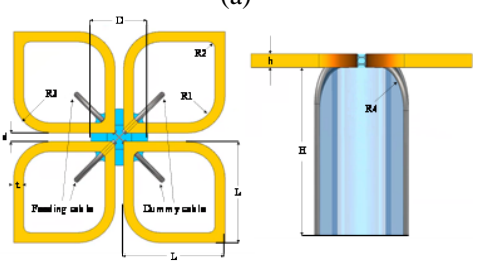

(b)

(c)

\section{SIMULATED RESULTS}

The simulated S-parameters of the proposed antenna are reported in Fig. 2. The input impedance fractional bandwidth is $53.5 \%$ for $\mathrm{S} 11<-14 \mathrm{~dB}$ (VSWR $<1.5$ ) with more than $59 \mathrm{~dB}$ of port-to-port isolation (S21 value with no sign). The radiation pattern at $2.4 \mathrm{GHz}$ with co and cross-polar components along E and H-plane is shown in Fig. 3. The antenna gain at boresight over the frequency is reported in Fig 4. The co-polar component is maintained between 8.3 and $9.3 \mathrm{dBi}$ while the cross-polar component is kept below $-48 \mathrm{dBi}$ within the bandwidth. The extremely low level of the latter as well as the high port-to-port isolation is the direct result of the highly balanced current distribution performed by the balun. In fact, 
for this antenna configuration, the use of ideal differential feeds instead of the proposed balun would provide values of port-toport isolation and cross polarization not far from the values obtained by employing the proposed balun, confirming thus the significant differential capability of the latter.

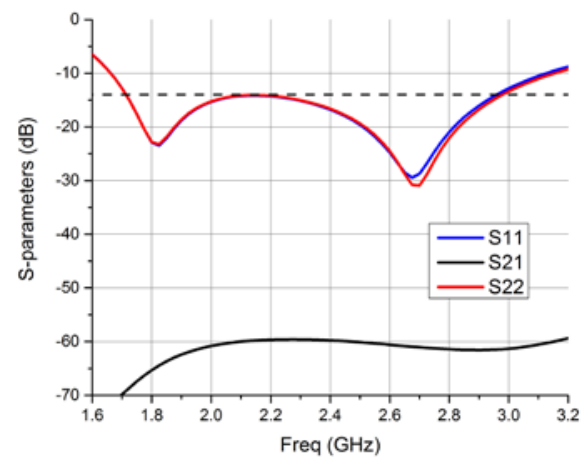

Fig. 2. Simulated S-parameters of the proposed antenna.

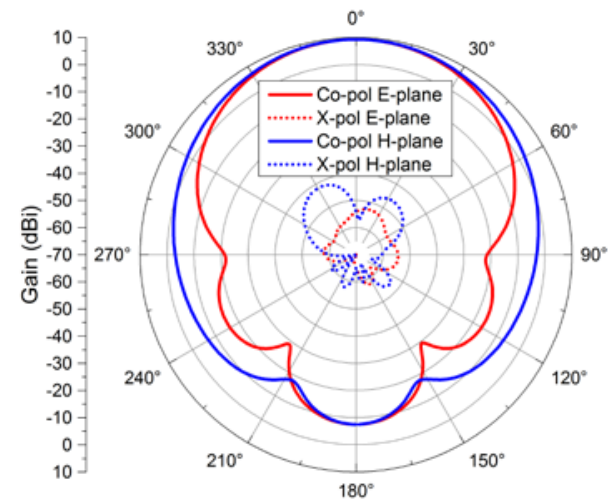

Fig. 3. Simulated radiation pattern at $2.4 \mathrm{GHz}$.
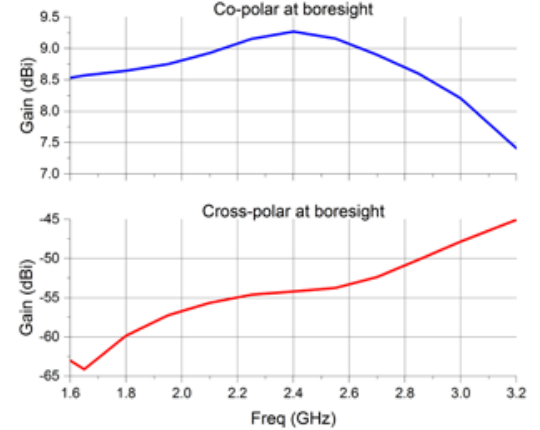

Fig. 4. Simulated co and cross-polar component at boresight.

\section{CONCLUSION}

In this paper a broadband dual-polarized antenna fed through a novel balun is proposed. The high degree of symmetry processed by the feeding structure provides superior antenna performance in terms of port-to-port isolation and polarization purity over a broadband operating range. These features as well as the compact size of the structure make the antenna very suitable for deployment in advanced multistandard base stations where volume is a premium.

\section{ACKNOWLEDGMENT}

This work was supported by Marie Curie European Industrial Doctorate (EID) programme ARTISAN (grant no. 316426).

\section{REFERENCES}

[1] Q. Wu and K. M. Luk, "A broadband dual-polarized magneto-electric dipole antenna with simple feeds," IEEE Antennas Wireless Propag. Lett., vol. 8, pp. 60-63, 2009.

[2] Q. X. Chu, D. L. Wen, Y. Luo, and X. J. Wang, "A broadband $\pm 45^{\circ}$ dual-polarized antenna with Y-shaped feeding structure,” IEEE Trans. Antennas Propag., vol. 63, no. 2, pp. 483-490, Feb. 2015.

[3] Z. D. Bao, Z. P. Nie, and X. Z. Zong, "A broadband dual-polarization antenna element for wireless communication base station," 2012 IEEE Asia-Pacific Conference Antennas Propag., pp. 144-146, Aug. 2012. 